\title{
Use of post-event surveys of impacts on railways for the evaluation of the IRIP method for surface runoff mapping
}

\author{
Lilly-Rose Lagadec ${ }^{1,2, a}$, Pascal Breil ${ }^{1}$, Blandine Chazelle ${ }^{2}$, Isabelle Braud ${ }^{1}$ and Loïc Moulin ${ }^{2}$ \\ ${ }^{1}$ IRSTEA, Hydrology-Hydraulics research unit, 5 rue de la Doua, CS 70977, 69626 Villeurbanne cedex, France \\ ${ }^{2}$ SNCF Réseau, Engineering and Projects, Lines-Track-Environment department, 6 avenue François Mitterrand, 93574 La-Plaine-Saint- \\ Denis cedex, France
}

\begin{abstract}
IRIP - Indicator of Intense Pluvial Runoff (French Acronym) - is a method to map the susceptibility of territories to surface runoff generation, transfer and accumulation. The method is based on a geomatic combination of landscape factors extracted from topography, land use and soil type. This study is part of the method evaluation process and suggests using information from post-event surveys of surface runoff events to evaluate the agreement between the IRIP maps and the field observations. Surface runoff susceptibility maps are produced at five meters resolution for three impact areas on railways with different infrastructure and environment configurations. First, information categories are extracted from the post-event surveys, and then the IRIP maps are analyzed to see if and how the information categories are retrieved. This study shows that the IRIP maps fit the impact description. The areas susceptible to surface runoff transfer fit the gullies locations and the areas susceptible to surface runoff accumulation fit the sediment deposit traces. The comparison also highlights that the IRIP maps can give further information on the event spatial dynamics. Given the simplicity and the robustness of the mapping method, IRIP can be a tool to perform surface runoff post-event surveys and to improve the surface runoff hazard assessment.
\end{abstract}

\section{Introduction}

Surface runoff is the part of precipitation that does not infiltrate into the soil and flows at the ground surface out of the permanent river network. The occurrence of surface runoff depends on multiple factors such as, rainfall patterns, soil properties and initial conditions, topography, land use and catchment geomorphology. Depending on these factors, surface runoff can have different characteristics: velocity, rheology, water depth and type of carried materials. In this study, surface runoff includes hazards such as soil erosion, mudslide, floods out of the river network and debris flow. The surface runoff hydrological process and related hazards can be difficult to observe and measure due to the quick and localized occurrence of the phenomena. The transportation network as outdoor infrastructure is impacted by meteorological and is particularly exposed to surface runoff [1], [2]. The linear and continuous nature of railways implies that they are likely to intercept natural water flow paths. They can be flooded, cluttered with materials and the structure itself can be swept away by the stream [2]-[5]. Thus, impacts on the railways are good indicators of surface runoff occurrence.

In terms of safety aspects and economic consequences, it is essential to reduce intense surface runoff related risks on the railway network. To manage these risks, it is essential to well understand the phenomenon and to know where it is the most susceptible to occur. Several methods allow the mapping of surface runoff, such as STREAM [6], SCALES [7], RuiCells [8], EXZECO [9] or Erruisoll [10]. In this paper, we focus on the IRIP method [11]-[14] - Indicator of Intense Pluvial Runoff (French Acronym) -. It is a geomatics method which produces maps of the spatial susceptibility of a territory to generate, to transfer and to accumulate surface runoff. The maps are created using a simple combination of landscape factors derived from topography, soil type and land use maps (see details in section 2.1).

Model evaluation is an important step in model development. Indeed, model outputs can be used by stakeholder for decision making. Wrong decisions can lead to severe consequences in terms of human impact and economic losses. So, it is important to understand the real meaning of model outputs, the assumptions, the range of application, the uncertainties. Concerning surface runoff maps, the evaluation is particularly complex because of the lack of surface runoff observations. Instrumentation and measurements are complex at large scale [11], [15]. Proxy data are an alternative to evaluate models. Proxy data are not direct measurements of the phenomenon but provide large-scale evidence of the phenomenon occurrence [16]. Proxy data used for model evaluation can be for example, road impacts [17]-[19], post-event surveys [21], [22] or insurance claims [22], [23]. These studies highlight methodological issues for the comparison of models with

\footnotetext{
$\overline{{ }^{a} \text { Corresponding author: lilly-rose.lagadec@irstea.fr }}$
} 
proxy data: difficulties to gather and format data and to process qualitative and non-exhaustive data..

The IRIP method has already been evaluated using many types of data. Spatially distributed observations in a small catchment allowed confirming the IRIP method concept of representing different steps of surface runoff (generation, transfer, accumulation) with different maps using different factors [11]. The IRIP method has been compared with others model outputs such as SHYREG [24], CINECAR and EXZECO [25] showing the complementarity of these models. Other works based on the comparison of the IRIP method with surface runoff coefficient from discharge data [26], [27] highlight the fact that surface runoff phenomenon is too much complex to be represented with only one runoff coefficient. . Large scale comparison has been made with the Gaspar French database of natural disaster claims [13] showing promising correlation. Statistical comparisons has been made with surface runoff impact locations on the transportation network, such as roads and railways [12], [14], [28] showing good correlation between the high susceptibility levels of the transfer and accumulation maps and the occurrence of surface runoff impacts. These works are part of the IRIP method evaluation process and show encouraging results but further works must be performed to evaluate the ability of the method for specific tasks. Focusing on specific events can allow evaluating the ability of the IRIP method to describe surface runoff events at very small scale, and can help establishing guidelines for the use of the IRIP maps in an operational context.

This study presents an analysis of three surface runoff impacts on the railway. The paper suggests a method to use information from the post-event surveys to evaluate the agreement between the IRIP maps and the impact circumstances. For each case study, six information categories are extracted from the post-event surveys, then, the IRIP maps are produced at a five meters resolution on the impacted area. The maps are analysed to see if the information provided by the survey are retrieved in the maps and how they are transcribed through the spatial information. Finally, interpretation keys of the IRIP maps are given and the contribution of the maps to carry out post-event survey is discussed.

\section{Materials and methods}

\subsection{The IRIP method}

IRIP is a method to produce maps of intense surface runoff susceptibility. The method allows producing three maps reflecting three surface runoff steps: generation, transfer and accumulation. The susceptibility map of surface runoff generation represents the areas the most susceptible to generate water at ground surface. The susceptibility map of surface runoff transfer represents the areas favourable to set surface water in motion, to accelerate it to make it more powerful. The susceptibility map of surface runoff accumulation represents the areas where surface runoff concentrates (talweg, hollows) or slows down in concave break of slopes and where water level can increase. The IRIP method concept is based on the analysis of different landscape factors that can be more or less favourable to surface runoff, and that the cumulative effects can lead to highly favourable conditions for surface runoff occurrence.

IRIP is a GIS based method. The map creation process is described on Figure 1. Multiple landscape indicators (Table 1, 2 and 3) of surface runoff occurrence susceptibility are derived from four input data: a Digital Elevation Model (DEM), a soil map, a land use map and the surface linear networks. From the DEM, are derived five indicators: the slope, the break of the slope, the topographic index [29], the form factor [30] and the flow accumulation. From the soil map, are derived three indicators: the soil permeability, thickness and erodibility. One indicator is derived from the land use map and another one from the surface linear network. Moreover, the map of surface runoff generation becomes an input indicator after reclassification for the two other maps. Topographical indicators are computed on each pixel relatively to the sub-catchment associated to the pixel. Each indicator can be either favourable or not favourable to surface runoff. At each pixel, 1 is attributed if the indicator is favourable to surface runoff and 0 if it is not favourable (Table 1, 2 and 3). Each of the three maps is created by adding 5 indicators. Therefore, the resulting maps are three susceptibility maps of surface runoff generation, transfer and accumulation, with a 0-to5 level scale ( 0 weakly susceptible and 5 highly susceptible).

For this study, a five meters DEM is used, provided by the French National Geographical Institute (IGN). For this reason no surface linear network is used for the creation of the transfer map; the fine resolution is supposed to already detect them. The used soil map is provided by IRSTEA research institute and the land use map is the Corine Land Cover 2012. A software version, called iRIPC) has been developed by SNCF (French National Train Company) for its own purpose and is used for this study.

The IRIP method produces susceptibility maps and is independent of the meteorological hazard. To get a surface runoff hazard map, the IRIP maps must be combined with the rainfall.

\begin{tabular}{|c|l|}
\hline Indicators & \multicolumn{1}{|c|}{ Values } \\
\hline \multirow{2}{*}{$\begin{array}{c}\text { Soil } \\
\text { permeability }\end{array}$} & $0:$ High permeability \\
\cline { 2 - 2 } Soil thickness & $1:$ Low permeability \\
\cline { 2 - 2 } & $0:$ Thick soil \\
\cline { 2 - 2 } $\begin{array}{c}\text { Soil } \\
\text { erodibility }\end{array}$ & $0:$ Thin soil \\
\cline { 2 - 2 } Topography & $1:$ High erodibility \\
\cline { 2 - 2 } & $0:$ Slope $<\mathrm{t}_{1}$ AND topographic index $<\mathrm{t}_{2}$ \\
\cline { 2 - 2 } Land use & $1:$ Slope $>\mathrm{t}_{1}$ OR topographic index $>\mathrm{t}_{2}$ \\
\cline { 2 - 2 } & $0:$ Infiltrative surfaces \\
\cline { 2 - 2 } & $1:$ Impervious surfaces \\
\hline
\end{tabular}

Table 1. The indicator used to create the IRIP map of surface runoff generation susceptibility and their possible values 


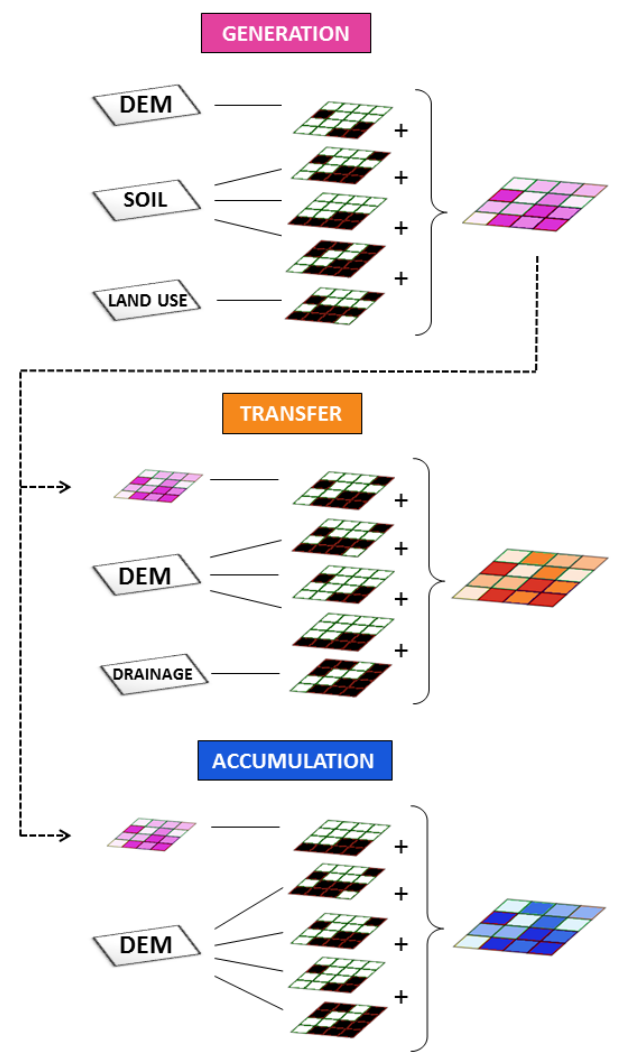

Figure 1. Scheme of the IRIP method and the combination of input data and of the map of generation to produce three maps of surface runoff generation, transfer and accumulation susceptibility on a six level scale, from 0 to 5

\begin{tabular}{|c|l|}
\hline Indicators & \multicolumn{1}{|c|}{ Values } \\
\hline \multirow{2}{*}{$\begin{array}{c}\text { Upstream } \\
\text { generation } \\
\text { susceptibility }\end{array}$} & $0:$ Upstream generation susceptibility \\
\cline { 2 - 2 } Slope & $1:$ No upstream generation susceptibility \\
\cline { 2 - 2 } & $0:$ Slope $<\mathrm{t}_{1}$ \\
\hline \multirow{2}{*}{ Breakslope } & $0:$ Clope $>\mathrm{t}_{1}$ \\
\cline { 2 - 2 } & $1:$ Concave break of slope \\
\hline \multirow{2}{*}{ Compacity } & $0:$ Low form factor \\
\cline { 2 - 2 } & $1:$ High form factor \\
\hline \multirow{2}{*}{$\begin{array}{c}\text { Surface linear } \\
\text { networks }\end{array}$} & $0:$ no linear axes \\
\cline { 2 - 2 } & $1:$ presence of linear axes \\
\hline
\end{tabular}

Table 2. The indicator used to create the IRIP map of surface runoff transfer susceptibility and their possible values

\begin{tabular}{|c|c|}
\hline Indicators & $\begin{array}{r}\text { Values } \\
\end{array}$ \\
\hline \multirow{2}{*}{$\begin{array}{c}\text { Upstream } \\
\text { generation } \\
\text { susceptibility }\end{array}$} & 0: Upstream generation susceptibility \\
\hline & 1: No upstream generation susceptibility \\
\hline \multirow{2}{*}{ Slope } & 0: Slope $>t_{1}$ \\
\hline & 1: Slope $<\mathrm{t}_{1}$ \\
\hline \multirow{2}{*}{ Breakslope } & 0: Convex break of slope \\
\hline & 1: Concave break of slope \\
\hline \multirow{2}{*}{$\begin{array}{l}\text { Topographic } \\
\text { index }\end{array}$} & 0: Topographic index $<\mathrm{t}_{2}$ \\
\hline & 1: Topographic index $>t_{2}$ \\
\hline \multirow{2}{*}{$\begin{array}{c}\text { Flow } \\
\text { accumulation }\end{array}$} & $\begin{array}{l}\text { 0: Low flow accumulation AND low } \\
\text { form factor }\end{array}$ \\
\hline & $\begin{array}{l}\text { 1: High flow accumulation OR high form } \\
\text { factor }\end{array}$ \\
\hline
\end{tabular}

Table 3. The indicator used to create the IRIP map of surface runoff accumulation susceptibility and their possible values
From previous studies conducted to assess the relevance of the IRIP maps, several points have been learnt and some hypotheses have been raised. When comparing the IRIP maps with risk regulatory zonings, there are agreements between the IRIP map of accumulation and the dry talweg network and between the IRIP map of transfer and soil erosion risk areas. However, some parts of the IRIP map of accumulation also correspond to soil erosion risk areas. The hypothesis is that the map of accumulation also shows the sediment deposit areas. The comparison between the IRIP maps and the post-event surveys allow discussing this hypothesis. Moreover, previous studies focused on the IRIP maps of transfer and accumulation. In this study the three maps are considered simultaneously.

\subsection{Data of surface runoff impact on railways}

Because of its linear features and its distribution on all types of territories, the railway network intercepts surface runoff. The railway longitudinal profile is very constrained to keep a steady incline platform. Thus, the railway transversal profile varies regarding the topography. There are three types of railway profile when crossing a hillslope: excavation (Figure 2.a) in rock or loose material, embankment (Figure 2.b) and mixed profile (Figure 2.c), which means excavation on the upstream side and embankment on the downstream side. The railway network being particularly exposed to waterrelated hazards is equipped with multiple hydraulic structures (aqueducts, nozzles...) and drainage devices (ditches, gutters, downspouts) to protect and to ensure hydraulic transparency [31]

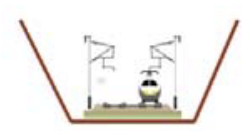

a. Excavation

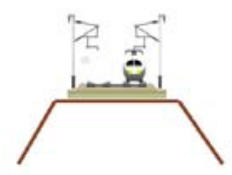

b. Embankment

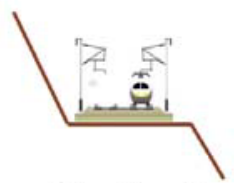

c. Mixed profile
Figure 2. Scheme of the three types of transversal profiles when the railway crosses a hillslope

Despite protective structures, intense surface runoff can impact the railway network. Disorders can be due to unsuitable state of hydraulic devices considering the initial runoff volume for which was dimensioned the structures. As soon as a disorder is detected or for particular rainfall events, organisational measures are taken to slow down or to stop train circulation regarding to the security aspects. Then, a field expertise allows making diagnostic to restore the line with its regular speed as soon as possible. This field expertise leads to post-event surveys. In this study these surveys are used as a source of information on the disorder circumstances to evaluate the relevance of the IRIP maps.

\subsection{Evaluation method}

This study focuses on a railway line in the Gard catchment $\left(2000 \mathrm{~km}^{2}\right)$, in the southern part of France. The 
Gard catchment is chosen due to its known exposition to intense Mediterranean rainfall events and intense surface runoff events which result from its topographical, geological and soil types [25]. The railway network crossing the catchment is about $70 \mathrm{~km}$ long. A preliminary analysis of multiple post-event surveys allowed selecting the three case studies which correspond to the three typical cross-profiles of a railway. The preliminary analysis of the surveys allowed identifying a set of six information categories: the meteorological event description, the impact description and location, the infrastructure description, the upstream environment description, the diagnosis about the disorder origins and causes made by the operator and the recommended measures that must be undertaken. These information categories allow analysing the post-event surveys rapidly and efficiently. Moreover, a mark is attributed to the information category in order to qualify its level of accuracy and uncertainty. The mark follows a simple three level scale: low if the information does not appear in the survey, medium if the information is discussed but incomplete or inaccurate; and strong if the information is complete and accurate.

So, the evaluation process focuses first on the postevent survey analysis. For the three examples, the six information categories are extracted and gathered in a table along with the mark. Then, a qualitative description of the event circumstances and the spatial surface runoff dynamic is written to summarize the event, and then a critical analysis is brought on the availability and quality of the post-event survey information.

Secondly, the evaluation process focuses on the IRIP maps analysis. For the three examples, the IRIP maps are produced for the catchment intercepted by the impacted railway section, with a five meter resolution DEM. A qualitative description is made about the catchment morphology and the three IRIP maps of surface runoff susceptibility. Then, the agreement between The IRIP maps and the survey is analysed. Does the impact description fit the IRIP maps? Which information category is better retrieved in the maps? Can the maps bring further information in the impact understanding? What is the benefit of each map (generation, transfer, accumulation)? From the six categories, impact, environment, diagnosis and recommended measures are analyses. The meteorological event and infrastructure categories are not appropriate to compare with the IRIP maps.

\section{Results}

\subsection{First case study: excavation profile}

\subsubsection{Information extracted from the post-event survey}

\begin{tabular}{|c|l|c|}
\hline Categories & \multicolumn{1}{|c|}{ Information } & Quality \\
\hline $\begin{array}{c}\text { Meteorological } \\
\text { event }\end{array}$ & No information & Low \\
\hline Impact & $\begin{array}{l}\text { No impact on the rails but } \\
\text { several shallow landslides }\end{array}$ & Medium \\
\hline
\end{tabular}

\begin{tabular}{|c|c|c|}
\hline & $\begin{array}{l}\text { from one to ten meters on the } \\
\text { upper part of the bank } \\
\text { upstream the railway. Few } \\
\text { years ago, surface runoff } \\
\text { caused the collapse of a } \\
\text { retaining wall at the same } \\
\text { location and also induced few } \\
\text { shallow landslides on several } \\
\text { parts of the bank upstream the } \\
\text { railway. }\end{array}$ & \\
\hline Infrastructure & $\begin{array}{l}\text { The railway is in a rock } \\
\text { excavation of fifteen meters at } \\
\text { the upstream side and five to } \\
\text { ten meters at the downstream } \\
\text { side. No information on } \\
\text { hydraulic structures. On the } \\
\text { upstream side the bank has } \\
\text { slopes of } 3 / 2 \text { and of } 3 / 1 \text { with a } \\
\text { berm in between. Few } \\
\text { retaining walls are located in } \\
\text { the lower part of the bank. } \\
\text { Several construction works } \\
\text { have been undertaken and the } \\
\text { slope has been consolidated } \\
\text { with poles and burlap. The } \\
\text { location and the dimension of } \\
\text { the structures on the bank are } \\
\text { not mentioned. }\end{array}$ & Strong \\
\hline Environment & $\begin{array}{l}\text { The bank is made of } \\
\text { calcareous, sandstones and } \\
\text { marls with alluvial terraces in } \\
\text { the upper part of the } \\
\text { catchment. The catchment } \\
\text { bounds are not identified. }\end{array}$ & Medium \\
\hline Diagnosis & $\begin{array}{l}\text { Intense rainfall saturated the } \\
\text { soil. Despite the presence of } \\
\text { burlap, the soil flowed down } \\
\text { on the steeper slopes. The } \\
\text { landslide was stopped by the } \\
\text { berm at middle slope. No } \\
\text { information on the others } \\
\text { landslides. }\end{array}$ & Medium \\
\hline $\begin{array}{l}\text { Recommended } \\
\text { measures }\end{array}$ & $\begin{array}{l}\text { increased monitoring } \\
\text { especially during severe } \\
\text { weather, rehabilitation of } \\
\text { burlap and seeding of the } \\
\text { slopes }\end{array}$ & Strong \\
\hline
\end{tabular}

Table 4. The six pieces of information extracted from the postevent survey for the first case study with their quality marks.

For this example, according to the post-event survey (Table 4), the damages did not impact the railway but have weakened the bank of the railway. Few shallow landslides from one to ten meters were observed. These landslides were stopped by the berm before the railway. Several consolidation works were undertaken on this bank, and the last one was the year of the last impact. This bank clearly suffers from geotechnical instability, but the reported impacts were induced by intense rainfall events. Surface runoff might not be the only cause of this disorder but is involve in the process. This area is nonetheless interesting to study because of the succession of impacts that indicates a local sensitivity.

Otherwise, in the survey, there is no information on the different meteorological events associated with the several disorders, and there is a good description of the 
railway infrastructures but no information about hydraulic devices. Moreover, there is little information about the role of the environment. The diagnosis is not complete for the different impacts but allows understanding the influence of the surface runoff. The recommended measures are clearly mentioned in the report.

\subsubsection{IRIP maps description}

The study railway section is 270 meters long and includes all the historical impact points. The catchment intercepted by the railway section is about 1.6 ha large with an elevation difference of 25 meters. This catchment is very small and presents steep slopes except on the railway and close to the headwater.

Figure 3 shows the three IRIP maps produced on the catchment. The IRIP map of generation susceptibility shows medium levels $(3 / 5)$ over the entire area. This is due to favourable slopes, land cover and soil erodibility. The IRIP map of transfer susceptibility also shows strong levels almost over the entire area (3 and 4/4) with pixels $4 / 4$ very close to the railway, which means that all the indicators are favourable to surface runoff transfer. The IRIP map of accumulation susceptibility shows strong levels $(4 / 5)$ on the railway. This is due to the railway profile which is established in an excavation. One can also see a slight persistence of medium level pixels $(3 / 5)$ in the middle of the slope.

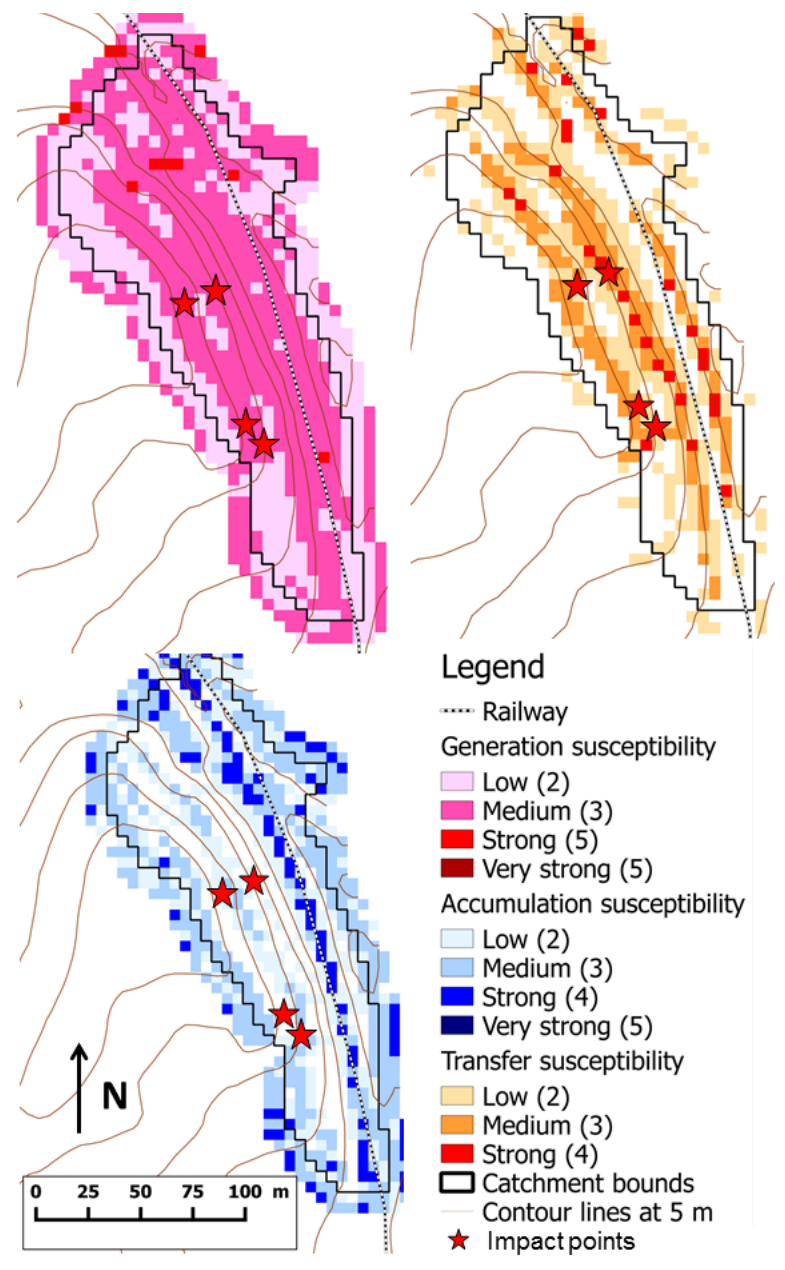

Figure 3. The three IRIP maps of surface runoff susceptibility for the first case study with approximated impact locations.

\subsubsection{Comparison between the post-event survey and the susceptibility maps}

In terms of impact description, the IRIP maps fit with the information in the survey. Indeed, there were on this catchment many shallow landslides on several points and the map of transfer susceptibility shows strong levels on the whole area. One can note an area with less transfer susceptibility, in the middle of the catchment, transversally to the slope and few pixels of higher accumulation susceptibility at the same location. This information marches with location of the berm, that is, the area where the landslides stopped. Moreover, one can note very high susceptibility for surface runoff transfer and accumulation very close to the railway whereas no impact has been reported on the tracks. It could be related to the retaining walls in the lower part of the bank that could protect the railway.

About the environment description, the IRIP map of accumulation shows medium susceptibility level of accumulation at the headwater of the catchment, in the middle and on the railway. This could correspond to the alluvial terraces, the berm and the railway excavation.

The diagnosis states that the soil was saturated by water and slipped along the slope. This scenario brings a new hypothesis concerning the IRIP map interpretation. Would the superimposition of high generation and transfer susceptibility be an indication of shallow landslide susceptibility?

Globally, this area shows a strong predisposition for two of the three surface runoff mechanisms on the whole area which fits with the monitoring recommended in the survey and planned bank consolidation and seeding. The accumulation map showing high susceptibility levels, the drainage devices must be regularly monitored and maintained if they exist.

\subsection{Second case study: the mixed profile}

\subsubsection{Information extracted from the post-event survey}

\begin{tabular}{|c|l|c|}
\hline Categories & \multicolumn{1}{|c|}{ Information } & Quality \\
\hline $\begin{array}{c}\text { Meteorological } \\
\text { event }\end{array}$ & $\begin{array}{l}300 \mathrm{~mm} \text { in } 13 \text { hours at a rain } \\
\text { gauge located 6 km away }\end{array}$ & Medium \\
\hline Impact & $\begin{array}{l}\text { Mudslide that covered the } \\
\text { track on about thirty meters } \\
\text { and filled the hydraulic } \\
\text { structures crossing below the } \\
\text { railway. Traces of materials } \\
\text { on the track surroundings at } \\
\text { few points. Gully erosion on } \\
\text { the banks upstream and } \\
\text { downstream the railway. }\end{array}$ & Strong \\
\hline Infrastructure & $\begin{array}{l}\text { The railway is established in a } \\
\text { mixed profile at this location. } \\
\text { There are three hydraulic } \\
\text { structures crossing below the } \\
\text { railway, the precise location } \\
\text { are mentioned. The railway is }\end{array}$ & Medium \\
\hline
\end{tabular}




\begin{tabular}{|c|c|c|}
\hline & $\begin{array}{l}\text { equipped with side ditches but } \\
\text { no information on the volume } \\
\text { neither on the maintenance } \\
\text { quality. }\end{array}$ & \\
\hline Environment & $\begin{array}{l}\text { A country road runs parallel } \\
\text { to the railway at about } 30 \\
\text { meters upstream. There is } \\
\text { vegetation between the road } \\
\text { and the railway. Above the } \\
\text { road there is a group of } \\
\text { buildings and construction } \\
\text { works. The land cover is } \\
\text { changing and the soil is bare. } \\
\text { Drainage systems have } \\
\text { changed and some drains } \\
\text { reject in the bank between the } \\
\text { road and the railway. }\end{array}$ & Strong \\
\hline Diagnosis & $\begin{array}{l}\text { Even though the rainfall event } \\
\text { was intense, the disorders are } \\
\text { due to the change in the land } \\
\text { cover that creates new } \\
\text { impervious surfaces and new } \\
\text { water flow paths. The } \\
\text { changes in the road drainage } \\
\text { systems redirect the surface } \\
\text { runoff in the bank upstream } \\
\text { the railway. }\end{array}$ & Strong \\
\hline $\begin{array}{l}\text { Recommended } \\
\text { measures }\end{array}$ & $\begin{array}{l}\text { Cleaning of the railway } \\
\text { platform, enlargement of the } \\
\text { road drainage capacity and } \\
\text { creation of a hydraulic } \\
\text { barricade at the beginning of } \\
\text { the bank toward the railway. }\end{array}$ & Strong \\
\hline
\end{tabular}

Table 5. The six pieces of information extracted from the postevent survey for the second case study with their quality marks.

For this example, according to the post-event survey (Table 5), the impact is due to an intense rainfall event and to the creation of new impervious surfaces. Moreover, there was creation of new surface runoff flow paths with a modification of the drainage systems that reject water toward the bank, directly upstream the railway. This induced intense gullies and material deposits on the railway and in the aqueducts and gullies again in the bank after downstream the railway.

Otherwise, in the survey, the impact is very well described and the environment as well. There is a good description of the infrastructure but a lack of information on the drainage condition and capacity. The diagnosis is accurate in the spatial dynamic of the event and the recommended measures as well.

\subsubsection{IRIP maps description}

The study railway section is 180 meters long and includes the impact point along with the aqueduct locations. The catchment intercepted by the railway section is about 4.8 ha large with a rounded shape and a elevation difference of 130 meters.

Figure 4 shows the three IRIP maps produced on the catchment. The IRIP map of generation susceptibility shows a high susceptibility for surface runoff generation in all the downstream part of the catchment near the railway with levels 3 and $4 / 5$. This is due to favourable soil thickness and erodibility with favourable slopes and topographic indexes. The IRIP map of transfer susceptibility also shows high levels on the railway track and in the whole downstream part between the railway and the country road. There are high densities of level 2 and $3 / 4$ and some isolated pixels of level $4 / 4$ very close to the railway, which means that all the indicators are favourable to surface runoff transfer. There is also a high susceptibility upstream the road in the northern part where slopes are steeper. The IRIP map of accumulation susceptibility shows high level pixels on the railway track, on the road and on the parking space. The map shows preferential flow paths both sides of the parking space but which do not persist until the railway. One can also see high susceptibility levels upstream the road (3 to $4 / 5)$.
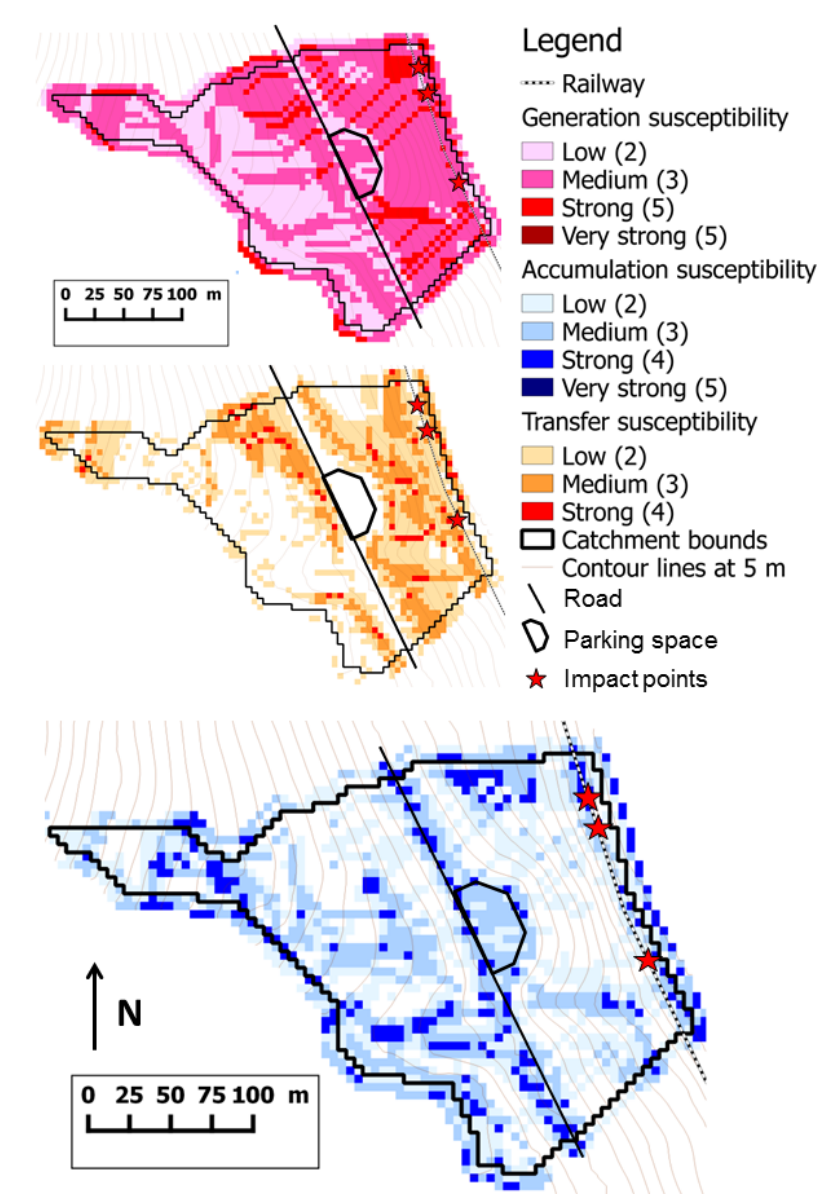

Figure 4. The three IRIP maps of surface runoff susceptibility for the second case study

\subsubsection{Comparison between the post-event survey and the susceptibility maps}

In terms of impact description, the IRIP maps matches with the information in the survey. Indeed, the transfer map shows strong transfer susceptibility between the road and the railway, which matches with the description of gullies at this location. The strong accumulation susceptibility on the railway matches with the information of material deposits on the railway track.

In terms of environment description, the IRIP maps can identify the road and the parking space by showing higher accumulation susceptibility. Even though the land 
cover between the road and the railway is not favourable to surface runoff (vegetation), all the others indicators are favourable which makes the railway section exposed to surface runoff, whereas it would not have been obvious from the railway view.

Even though the diagnosis blames the change in the land cover and the drainage facilities in the occurrence of the damages, the catchment shows high susceptibility to surface runoff for the three maps near the railway. So this area was predisposed to surface runoff. It would be interesting to look for more information on the historic impact in this area. May the aqueduct dimensions have been adequate considering the environment before the change in land use?

Regarding the recommended measures, it is indeed important to enlarge the drainage capacity of the road. Moreover, since the bank between the road and the railway is very susceptible to generate and transfer surface runoff, it would be interesting to perform hydraulic studies in order to assess the possibility of ditches creation along this bank.

\subsection{Third case study: the embankment profile}

\subsubsection{Information extracted from the post-event survey}

\begin{tabular}{|c|c|c|}
\hline Categories & Information & Quality \\
\hline $\begin{array}{c}\text { Meteorological } \\
\text { event }\end{array}$ & No information & Low \\
\hline Impact & $\begin{array}{l}\text { Accumulation of water } \\
\text { behind the railway } \\
\text { embankment. Four water } \\
\text { resurgence points on the } \\
\text { downstream part of the } \\
\text { embankment, with the } \\
\text { mentioned location. The } \\
\text { water resurgence created } \\
\text { gullies on the other side of the } \\
\text { embankment. No mud deposit } \\
\text { neither land levelling } \\
\text { problem. }\end{array}$ & Strong \\
\hline Infrastructure & $\begin{array}{l}\text { The embankment is } 3 \text { to } 5 \\
\text { meters high and surrounded } \\
\text { by two mixed profile, no } \\
\text { hydraulic structure to cross } \\
\text { under the railway at this point }\end{array}$ & Strong \\
\hline Environment & $\begin{array}{l}\text { A talweg transversal to the } \\
\text { railway. Calcareous rock } \\
\text { except in the talweg bottom } \\
\text { where there is a clay layer. } \\
\text { The environment description } \\
\text { focuses on the railway } \\
\text { surroundings. The catchment } \\
\text { is plotted on a map but the } \\
\text { catchment head is } \\
\text { approximated. }\end{array}$ & Medium \\
\hline Diagnosis & $\begin{array}{l}\text { Accumulation of surface } \\
\text { runoff from the talweg but no } \\
\text { information on the } \\
\text { contributing areas. The lack } \\
\text { of hydraulic structure for } \\
\text { water crossing is the main } \\
\text { cause of water accumulation. }\end{array}$ & Medium \\
\hline
\end{tabular}

\begin{tabular}{|c|c|c|}
\hline & $\begin{array}{l}\text { The material heterogeneity in } \\
\text { the embankment gave } \\
\text { preferential ways for water } \\
\text { infiltration. No comment on } \\
\text { the upstream environment } \\
\text { configuration. }\end{array}$ & \\
\hline $\begin{array}{l}\text { Recommended } \\
\text { measures }\end{array}$ & $\begin{array}{l}\text { Filling of gullies and } \\
\text { increased monitoring } \\
\text { especially during severe } \\
\text { weather. Ask for hydraulic } \\
\text { studies, estimation of the } \\
\text { rainfall of the event and } \\
\text { research for old hydraulic } \\
\text { structure to cross the railway. } \\
\text { Check the catchment } \\
\text { headwater boundaries where } \\
\text { there is a landfill and check } \\
\text { their water management. }\end{array}$ & Strong \\
\hline
\end{tabular}

Table 6. The six pieces of information extracted from the postevent survey for the third case study with their quality marks.

For this example, according to the post-event survey (Table 6), the talweg concentrated surface runoff from upstream without giving hypothesis on the contributing areas. Surface runoff was accumulated behind the railway embankment which did not have any hydraulic structure for water to cross the railway. The water accumulated in the depression pushed toward the embankment and found preferential paths to flow throughout it. Four resurgence points were observed resulting in gullies formation.

Otherwise, in the survey, there is no information on the type of meteorological event and information about the spatial dynamic of surface runoff only focuses on the meeting point with the railway. The catchment is not fully described and its bounds are not clearly defined. There are questions on the inclusion of the landfill in the catchment headwater. On the contrary, there are good descriptions of the infrastructure and of the historic impacts of the area. The report shows that the survey focuses on the impacted point and remains in the near environment of the railway.

\subsubsection{IRIP maps description}

The study railway section is 330 meters long and includes the impact point and the water resurgence points. The catchment intercepted by the railway section is 29 ha large. It has an elongated shape in the downstream part with a talweg well defined, and has a spread out shape in the upstream part with two terraces separated with a drop of fifteen meters. The elevation difference of the catchment is of 45 meters. The catchment drawn with the IRIP method with a five meter resolution DEM is different from the catchment in the survey. The IRIP maps include the landfill in the catchment.

Figure 5 shows the three IRIP maps produced on the catchment. The IRIP map of generation susceptibility shows low susceptibility levels (less than 2) in the downstream part of the catchment and higher levels (3 and 4/5) in the upstream part. This is due to the presence of the landfill, which makes the soil hydraulic properties favourable to surface runoff (thickness and permeability). 
The levels $4 / 5$ are due to favourable slopes and topographic indexes. On the contrary, the lower part of the catchment has a thick soil with low erodibility and a vegetation type land cover. The IRIP map of transfer susceptibility does not show high susceptibility levels near the railway. There are levels 2 at $3 / 4$ in the talweg side due to the compactness index, the slope and the break in the slope. In the upper part of the catchment there are levels 3 and $4 / 4$ due to the generation map that shows high susceptibility levels in this area. One can also notice susceptibility levels of 3 and $4 / 4$ directly downstream the railway (Figure 6). The IRIP map of accumulation susceptibility shows a well-defined talweg with susceptibility levels of $4 / 5$ because of the favourable slope, break in slope and a post-processing of filling the surrounding pixels lower in elevation). The map also shows high susceptibility levels near the railway (Figure 7). One can notice a high density of level $3 / 5$ and many isolated pixels of level 4/5. The upper part of the catchment shows accumulation susceptibility levels of 3 and $4 / 5$.

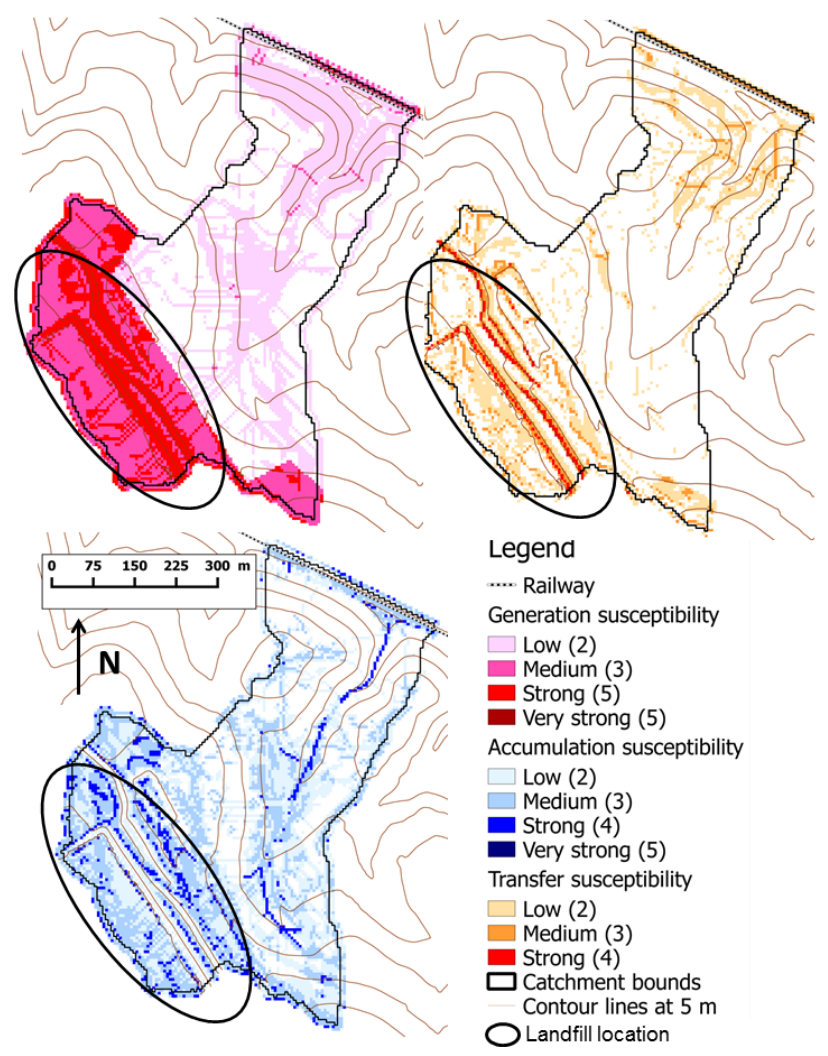

Figure 5. The three IRIP maps of surface runoff susceptibility for the third case study

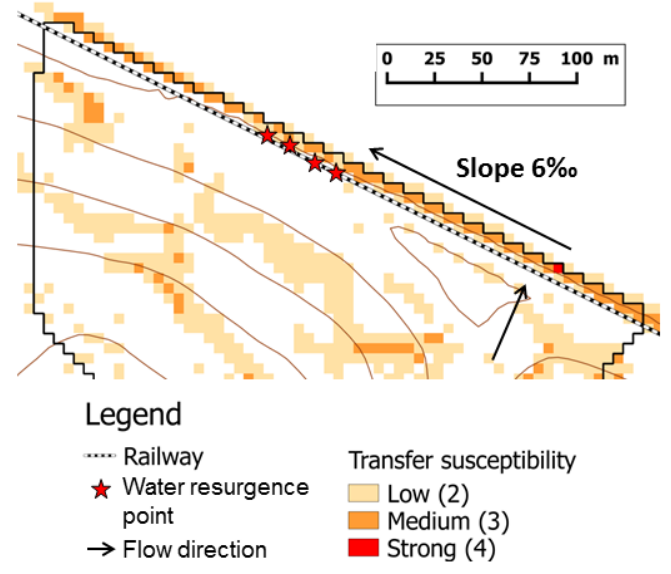

Figure 6. Focus on the IRIP map of surface runoff transfer susceptibility to show the agreement between the impact description and the spatial information of the map

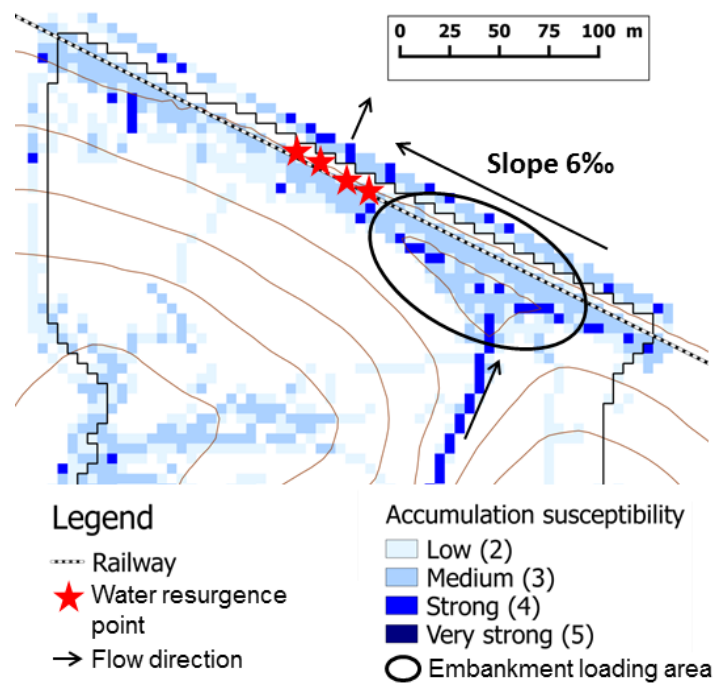

Figure 7. Focus on the IRIP map of surface runoff accumulation susceptibility to show the agreement between the impact description and the spatial information of the map

\subsubsection{Comparison between the post-event survey and the susceptibility maps}

About the impact description, the causal interpretation made with the IRIP maps seems to suit. Indeed, the accumulation map shows a strong density of pixels $3 / 5$ and many pixels $4 / 5$ at the meeting point of the talweg and the railway. This can correspond to the filling of the hollow by water and the loading of the railway embankment. Moreover, there are strong susceptibility levels all along the railway, even near the resurgence points, that are not in the talweg axis. The survey also states that there was no mud deposit. When focusing on the transfer map, no high susceptibility levels are observed in the catchment near the railway (pixels 2/4 and few 3/4), except in the upstream part where strong pixels (4/4) are located at 650 meters from the railway. Could the distance have been too long to be able for water to transport material until the railway? Did the accumulation area in between have played a role in the sediment deposit? Moreover, the strong transfer 
susceptibility directly downstream the railway could correspond to gullies formed after the resurgence points.

Regarding the environment description in the survey which mentioned the talweg, the accumulation map indeed shows a well-defined talweg. The survey also ask question about the inclusion of the landfill in the catchment and the IRIP shows that it is partially included. It is thus possible that this surface contributed to surface water generation since it represents about 8.5 ha of levels 3 and $4 / 5$ according to the generation map.

Even though the post-event survey provides little information about the surface runoff spatial dynamic and points out the absence of hydraulic structure, the IRIP map allows making some assumptions. For instance, surface runoff could have been generated on or near the landfill area. Surface runoff could have been accumulated in the talweg until the railway, and then accumulated behind the embankment and flow along the railway following the slight slope until crossing the embankment, where topography and materials are more propitious. However, others scenario can be suggested. Subsurface and ground water could have played a role in the filling of the talweg and of the hollow behind the embankment. Nonetheless, the absence of hydraulic structure for crossing the railway suggests that this talweg is dry, most of the time. Another suggestion is that the calcareous rock of this area can have an active water network and some natural resurgence points can be at the origin of the amount of water. This suggestion corresponds with the fact that there was no mud deposit.

Regarding the recommended measures, it could be indeed interesting to assess the contribution of the landfill by analysing the water management and by comparing the historic impacts on the railway with the creation date of the landfill. Moreover, it seems important to analyse the rainfall event in order to assess the part of surface and subsurface water in the filling of the talweg.

\subsection{Result summary}

The comparison between the post-event surveys and the IRIP maps allow evaluating the relevance of the surface runoff susceptibility maps with field observation. Table 7 shows the result summary for the three case studies. Globally, the IRIP maps fit with the field observation, particularly with the impact description, but in many cases the lack of information exhaustiveness does not allow a complete analysis, for example information about the rainfall event is essential for the diagnosis. Further field expertise is also needed to fully validate the maps on these case studies. The evaluation process must be also pursued for more examples, for different catchment sizes and geographical contexts. However, these comparisons allow discussing about the initial hypothesis and move towards certainties.

\begin{tabular}{|c|c|c|c|}
\hline Information categories & \multicolumn{3}{|c|}{$\begin{array}{c}\text { Agreement with the IRIP } \\
\text { maps }\end{array}$} \\
\hline Parameters & $1^{\text {st }}$ case & $2^{\text {nd }}$ case & $3^{\text {rd }}$ case \\
\hline Meteorological event & & & \\
\hline Impact & Good & Good & Good \\
\hline Infrastructure & & & \\
\hline Environment & Partial & Good & Good \\
\hline Diagnosis & Partial & Partial & Partial \\
\hline Recommended measures & Good & Good & Good \\
\hline
\end{tabular}

Table 7. Result summary of the agreement between the IRIP maps and the pieces of information extracted from the post-event surveys.

\section{Discussions and perspectives}

The analysis of these three case studies allows making global comments on the post-event survey relevance and shortcomings and on the information and uncertainties brought by the IRIP maps. The comparison between the surveys and the maps also allow giving interpretation keys for the use of the IRIP maps as a tool for making diagnostics.

\subsection{Remarks on the post-event surveys}

Despite the simplicity of the scale about the information quality, differences in uncertainty and accuracy are noteworthy. The accuracy depends on the event and also on the information categories. First, the information on the meteorological event is almost never mentioned whereas the recommended measures are very precise. This observation is not surprising but reveals the operational point of view of these surveys. The objectives of the post-event survey are more to protect the infrastructure and to allow train circulation than to understand the rainfall event and the flow of water on the ground. Nevertheless, rainfall information can be obtained a posterior to enrich the event circumstances analysis. The information quality of the others categories is medium or strong. It reveals that information on impacts, infrastructure and diagnosis is rather well usable to understand the event (two strong and one medium). Nonetheless, the infrastructure description does not inform completely on the configuration of the hydraulic structures and their capacities or on the level of maintenance. The environment configuration description is rather incomplete (two medium and one strong). It often remains at view distance from the railway and does not inform on the contributing areas. However, good quality information is important in all categories. It is essential to detect the origin of the dysfunction and the aggravating factors in order to take the appropriate measures and to prevent further disorder. This strategy leads to a sustainable development of the railway infrastructure in its environment. 


\subsection{Remarks on the IRIP maps}

\subsubsection{Map uncertainties}

The IRIP maps bring much information on the environment. They give information on the catchment bounds and on the surface runoff spatial sensitivity within the catchment. The maximum level of susceptibility is computed respectively to the study catchment, which means it cannot be compared between catchments as an absolute value. However, in the case of already observed events, it means that surface runoff issues exist despite of an absolute scale. The activation of areas prone to surface runoff will also depends on the rainfall intensity spatial distribution, which is not included at the moment in the method. The interest to keep the maximum susceptibility level relative to the study area is also to keep the most detailed information that IRIP can provide.

The maps also allow making some assumptions about the spatial dynamic of surface runoff, but the analysis must keep in mind the uncertainties contained in the IRIP maps. Uncertainties can be due to the input data: on the topography quality, the land use map completeness or the soil map accuracy. Moreover, the IRIP maps are raw outputs of the indicator combination. They can be calibrated regarding knowledge on the study area (i.e. slope thresholds, geology influence on soil properties, land cover particularities). The susceptibility levels also can be difficult to interpret in terms of isolated pixels, size of a sensitive area, pixel density, meaning of a medium susceptibility level, distance between high susceptibility levels and the impact area. The interpretation of these pixel configurations can also differ for the three maps and with the resolution.

\subsubsection{Relationships between IRIP maps and natural phenomena}

About the relationship between the different IRIP maps and the natural phenomenon, the three cases allow making a link between the transfer susceptibility map and the soil erosion phenomenon. The first and the second cases show erosion and shallow landslide phenomena and both present a transfer map with a lot of strong susceptibility levels near the impact points. The third case is not concerned by an erosion phenomenon and present low transfer susceptibility. About the accumulation map, it can be confirmed with the three cases that it informs not only on the flooded area but also on areas with sediment deposit susceptibility. The first case shows the pixels of levels 3, associated to a berm, could have stopped the shallow landslides and protected the track. The second case shows high accumulation susceptibility on the track which has been covered by material deposits. The third case must be confirmed with further expertise but suggests that the accumulation susceptibility in the middle of the catchment with pixels of level 3 could have stopped the sediment transport from the upstream part of the catchment which presents high levels of transfer susceptibility. About the relationship between the three maps, this study allows suggesting that when at least two maps on three present high susceptibilities, the area is globally more exposed to surface runoff issues. The first case gather generation and transfer high susceptibility on the whole catchment, the second case gather high susceptibility for the three IRIP maps near the impact points, and the third case gather high accumulation susceptibility and high generation susceptibility but more upstream in the catchment.

\subsubsection{The IRIP susceptibility levels}

About the susceptibility levels, this study allows raising few hypotheses. The third case suggests that the transfer susceptibility of level 2 would not be significant since no any trace of soil erosion was observed. Otherwise, transfer susceptibility characterised by a strong density of level 3 with few pixels of level 4 seems to be significant for representing an exposed area (cases 1 and 2). About the accumulation map, few level 3 pixels would be significant to slow down and intercept sediment transport, according to the first and the third cases. Moreover, according the third case, a strong density of level 3 with few level 4 pixels would represent an area exposed to flooding. About the susceptibility levels of transfer and accumulation these case studies show that despite strong transfer susceptibility, accumulation susceptibility of level 3 could be enough to intercept sediment deposit.

\subsubsection{The IRIP map of surface runoff generation susceptibility}

About the spatial information of the IRIP map of surface runoff generation susceptibility, the analysis of the third case allows raising the hypothesis of the influence of the area size and distance. Pixels with susceptibility levels of 3 and 4 represent about one third of the total catchment area, and are located about 650 meters away from the railway. According to the amount of accumulated water behind the embankment and that loaded it until passing throughout it, the significant surface favourable to surface runoff generation could have played an important role. This hypothesis must be further developed and more events must be analysed.

\subsection{IRIP as a tool for post-event surveys}

This study is part of the IRIP method evaluation process. This analysis relies on results from past studies and provides further discussions on assumptions. A fine tuning of IRIP maps is not the objective because the IRIP method aims to be as robust as possible, knowing that input data precision can vary from a place to another. The evaluation challenge is then for IRIP to verify that predicted processes (erosion, deposits, runoff pathways) are confirmed anywhere and despite of the quality of the input data. The presented results show a good agreement with previous observations made in other locations and tend to confirm the robustness of the method. For now, the evaluation of the IRIP maps tends to confirm that the 
method can be applied successfully in different geological and climatic areas but it still requires more cases of application to confirm its predictability capacity. IRIP provides very simplified view of the surface runoff spatial dynamics, and therefore, will never fully match field reality. However, with more and more tests, the meaning of the maps and the information quality and uncertainty can be qualified and quantified. Tests allow identifying certain tasks in which the IRIP maps can bring valuable information. This study allows showing the contribution of the IRIP maps for performing postevent surveys.

The tasks in which the IRIP maps can contribute is, for example, the work of prior field identification in order to efficiently organize field expertise. This could allow better understanding the environment, that is, the identification of the catchment bounds and of the susceptibility of some areas to surface runoff generation, transfer or accumulation. The post-event survey analysis allowed showing the uncertainties about the environment description whereas impact descriptions and diagnostics are fully described. During field expertise, having such maps could allow better knowing what is important to check in which area (for example, soil erosion traces in high transfer susceptibility areas and sediment deposit or water marks in high accumulation susceptibility areas).

Further analyses must be performed in order to assess the ability of the IRIP method to identify exposed area along railway lines and prioritize areas for increased monitoring or maintenance. Further tests must be also performed to assess the contribution of the IRIP method in the infrastructure construction and design, for instance to choose hydraulic structure device and location. Moreover, having different surface runoff maps showing different mechanisms could allow adapting risk management technics depending on the area and the dominant process (for instance to encourage soil infiltration in areas with high susceptibility to surface runoff generation, or to avoid obstacles or redirect runoff in areas with high transfer susceptibility). As, the HYDRATE project [32] which provides guidelines for post-flood investigation, intense surface runoff event should have a global strategy of observation. From an operational point of view, post-event survey must be homogenized in order to optimized and make effective the management of intense surface runoff related impacts. From a scientific point of view these post-event surveys must constitute an important source of information to learn about the surface runoff phenomenon and to better evaluate models.

\section{Conclusions}

Considering the three typical cross-sections of a railway when crossing hillslopes, the IRIP method has shown to be effective to identify the impact types and locations caused by surface runoff in each of the crosssections.

To resume the major findings of this paper:

- In the excavation profile (case 1) IRIP indicates susceptibility to erosion in the artificial bank and runoff accumulation on the railway. The first consequence is confirmed while the second is not, maybe in reason of protective structures in the lower part of the bank.

- In the mixed profile (case 2), IRIP also indicates susceptibility to erosion of the upstream and downstream bank with also accumulation on the railway. It is again confirmed by gullies and deposits.

- In the embankment profile (case 3), IRIP indicates susceptibility to accumulation behind the railway embankment which blocks the overland runoff, and erosion on the downstream part of the embankment by overflow or percolation, which is again confirmed.

The physical processes and their causes seems to be obvious but their occurrence is not so predictable without an integrated analysis of the upstream catchment. That is what the IRIP method can bring.

\section{Acknowledgements}

We thank ANRT (Agence Nationale de la Recherche et de la Technologie) for funding the $\mathrm{PhD}$ grant of the first author. We thank Judicaël Dehotin who developed the software implementing the IRIP method, Oumaïma Benarina for her useful reflexions on the transportation network vulnerability in the Gard basin, all the colleagues who contributed to the IRIP method development and evaluation, Olivier Payrastre for fruitfull discussions about this work.

\section{References}

[1] B. Chazelle, L. Lambert, and C. P. Capoccioni, 'Railway vulnerability in case of extremes floods. Knowledge and risk management', Houille Blanche, no. 2, pp. 48-54, 2014.

[2] C. Pams-Capoccioni, D. Nivon, J. Amblard, G. De cesare, and T. Ghilardi, 'Risk analysis for railway traffic of overflowing of the drainage system on High Speed Lines.', Houille Blanche, no. 4, pp. 39-45, 2015.

[3] J. Amblard, C. P. Capoccioni, D. Nivon, L. Mellal, G. De Cesare, T. Ghilardi, M. Jafarnejad, and E. Battisacco, 'Analysis of Ballast Transport in the Event of Overflowing of the Drainage System on High Speed Lines', Int. J. Railw. Technol., vol. 4, no. EPFL-ARTICLE-215824, pp. 19-43, 2015.

[4] J. Dehotin, B. Chazelle, L. Lambert, P. Breil, I. Braud, C. Pams Capoccioni, J. Amblard, and L. Mellal, 'Diagnostic de l'impact du ruissellement sur la plateforme ferroviaire avec la méthode IRIP', Symp. Int. GEORAIL, p. 11, 2014.

[5] N. Tennakoon, B. Indraratna, C. Rujikiatkamjorn, S. Nimbalkar, and T. Neville, 'The Role of BallastFouling Characteristics on the Drainage Capacity of Rail Substructure', Geotech. Test. J., vol. 35, no. 4, p. 104107, Jul. 2012.

[6] O. Cerdan, V. Souchère, V. Lecomte, A. Couturier, and Y. Le Bissonnais, 'Incorporating soil surface crusting processes in an expert-based runoff model: sealing and transfer by runoff and erosion related to 
agricultural management', Catena, vol. 46, no. 2, pp. 189-205, 2002.

[7] P. Le Gouee, D. Delahaye, M. Bermond, M. Marie, J. Douvinet, and V. Viel, 'SCALES: a large-scale assessment model of soil erosion hazard in BasseNormandie (northern-western France)', Earth Surf. Process. Landf., vol. 35, no. 8, pp. 887-901, Jun. 2010.

[8] J. Douvinet, M. J. V. D. Wiel, D. Delahaye, and E. Cossart, 'A flash flood hazard assessment in dry valleys (northern France) by cellular automata modelling', Nat. Hazards, vol. 75, no. 3, pp. 29052929, Oct. 2014.

[9] F. PONS, J.-L. DELGADO, P. GUERO, and E. BERTHIER, 'EXZECO: a gis and dem based method for pre-determination of flood risk related to direct runoff and flash floods', presented at the 9th International Conference on Hydroinformatics, Tianjin, CHINA, 2010.

[10] P. Demarcin, A. Smoos, S. Dautrebande, A. I. Mokadem, and A. Degre, 'ERRUISSOL project or the mapping of areas at risk of runoff and erosion in the Walloon Region (Belgium)', presented at the 10èmes Journées d'étude des sols, Strasbourg FRA, 2009.

[11] J. Dehotin, P. Breil, I. Braud, A. de Lavenne, M. Lagouy, and B. Sarrazin, 'Detecting surface runoff location in a small catchment using distributed and simple observation method', J. Hydrol., vol. 525, pp. 113-129, Jun. 2015.

[12] J. Dehotin, B. Chazelle, G. Laverne, A. Hasnaoui, L. Lambert, P. Breil, and I. Braud, 'Applying runoff mapping method IRIP for flooding risk analysis on railway infrastructure', Houille Blanche, no. 6, pp. 56-64, 2015.

[13] J. Dehotin and P. Breil, 'Technical report of the IRIP project: mapping the flooding by runoff', IRSTEA Hydrology-Hydraulic Research Unit, Technical report, Jul. 2011.

[14] L.-R. Lagadec, P. Patrice, B. Chazelle, I. Braud, J. Dehotin, E. Hauchard, and P. Breil, 'Description and evaluation of an intense surface runoff susceptibility mapping method', J. Hydrol., 2016.

[15] N. Hudson, Field measurement of soil erosion and runoff, vol. 68. Food \& Agriculture Org., 1993.

[16] IPCC, 'IPCC Third Assessment Report - Climate Change 2001: 2.3.2.1 Palaeoclimate proxy indicators', 2003.

[17] J.-P. Naulin, O. Payrastre, and E. Gaume, 'Spatially distributed flood forecasting in flash flood prone areas: Application to road network supervision in Southern France', J. Hydrol., vol. 486, pp. 88-99, Apr. 2013.

[18] P.-A. Versini, E. Gaume, and H. Andrieu, 'Assessment of the susceptibility of roads to flooding based on geographical information - test in a flash flood prone area (the Gard region, France)', Nat. Hazards Earth Syst. Sci., vol. 10, no. 4, pp. 793-803, 2010.

[19] P.-A. Versini, E. Gaume, and H. Andrieu, 'Application of a distributed hydrological model to the design of a road inundation warning system for flash flood prone areas', Nat. Hazards Earth Syst. Sci., vol. 10, no. 4, pp. 805-817, 2010.

[20] P. Javelle, J. Demargne, D. Defrance, J. Pansu, and P. Arnaud, 'Evaluating flash-flood warnings at ungauged locations using post-event surveys: a case study with the AIGA warning system', Hydrol. Sci. J., vol. 59, no. 7, pp. 1390-1402, Jul. 2014.

[21] K. L. Ortega, T. M. Smith, K. L. Manross, A. G. Kolodziej, K. A. Scharfenberg, A. Witt, and J. J. Gourley, 'The severe hazards analysis and verification experiment', Bull. Am. Meteorol. Soc., vol. 90, no. 10, pp. 1519-1530, 2009.

[22] D. Bourguignon, 'Événements et territoires-le coût des inondations en France: analyses spatiotemporelles des dommages assurés', Université Paul Valéry-Montpellier III, 2014.

[23] J. Douvinet, 'Intérêts et limites des données «CatNat» pour un inventaire des inondations. L'exemple des «crues rapides » liées à de violents orages (Bassin parisien, Nord de la France)', Norois Environ. Aménage. Société, no. 201, pp. 17-30, Dec. 2006.

[24] P. Arnaud and J. Dehotin, 'Surface runoff hazard estimation methods - Comparison of the SHYREG and the IRIP methods', IRSTEA Aix-en-Provence et IRSTEA Lyon, Dec. 2011.

[25] O. Benarina, 'Intense surface runoff related flood modeling for the prediction and prevention of cuts of roads and railway lines.', IRSTEA Lyon, Master thesis, 2015.

[26] A. Hasnaoui, 'Utilisation de la méthode IRIP pour l'estimation des débits des bassins versants non jaugés', SNCF Projets Systèmes Ingénierie, Mémoire de fin d'études, Sep. 2013.

[27] J. Legros, 'Study of datas gived by a method of flooding harzard by surface runoff in flow discharge modelling linked with this kind of flooding', IRSTEA Hydrology-Hydraulic Research Unit, Master thesis, Sep. 2014.

[28] L. Mellal, 'Application de la méthode de cartographie du ruissellement IRIP (Indicateur du Ruissellement Intense pluvial) sur la ligne à grande vitesse Paris-Lyon', SNCF Projets Systèmes Ingénierie, Mémoire de fin d'études, Sep. 2014.

[29] K. J. Beven and M. J. Kirkby, 'A physically based, variable contributing area model of basin hydrology / Un modèle à base physique de zone d'appel variable de l'hydrologie du bassin versant', Hydrol. Sci. J., vol. 24, no. 1, pp. 43-69, 1979.

[30] R. E. Horton, 'Drainage-basin characteristics', Trans. Am. Geophys. Union, vol. 13, no. 1, p. 350, 1932.

[31] F. J. Heyns, 'Railway track drainage design techniques', Dr. Diss. Available Proquest, pp. 1354, Jan. 2000.

[32] E. Gaume and M. Borga, 'State of the art on the knowledge recently acquired on flash floods in Europe: results of the European research project HYDRATE (2006-2010)', Houille Blanche-Rev. Int. Eau, no. 2, pp. 24-30, Apr. 2013. 